\title{
O corpo e o saber médico no século XVIII: entrevista com Jean Abreu
}

\author{
The body and the medical knowledge in the eighteenth century: \\ an interview with Jean Abreu
}

Entrevista com

Jean Luiz Neves Abreu

Professor, Programa de Pósgraduação em História/

Universidade Federal de Uberlândia.

Av. João Naves de Ávila, 2121 Campus Santa Mônica - Bloco H 35020-220 - Uberlândia - MG Brasil

jluiz@inhis.ufu.br

\section{Concedida a}

\section{Lucas Samuel Quadros}

Mestrando, Programa de Pós-graduação em História/ Universidade Federal de Ouro Preto (Ufop).

Rua do Seminário, s.n.

35420-000 - Mariana - MG - Brasil

lucassquadros@yahoo.com.br

\section{Vinícius Paulo Gelape}

Graduando em História/Ufop. Rua do Seminário, s.n. 35420-000 - Mariana - MG - Brasil viniciuspaulo34@hotmail.com

\section{Maria Cristina Rosa}

Professora, Departamento de Educação Física/Universidade Federal de Minas Gerais.

Av. Antônio Carlos, 6627

31270-901 - Belo Horizonte - MG

- Brasil

m.crosa@hotmail.com
QUADROS, Lucas Samuel; GELAPE, Vinícius Paulo; ROSA, Maria Cristina. O corpo e o saber médico no século XVIII: entrevista com Jean Abreu. História, Ciências, Saúde - Manguinhos, Rio de Janeiro, v.22, n.2, abr.-jun. 2015, p.593-604.

\section{Resumo}

A história das ciências é área reconhecida e em plena expansão no Brasil, porém alguns temas ainda são pouco abordados nas pesquisas, como a medicina no período colonial. Com o intuito de privilegiar esse assunto realizou-se esta entrevista com o professor Jean Luiz Neves Abreu, importante pesquisador da história da medicina no Império luso-brasileiro do século XVIII. Ao abordar sua trajetória, experiência acadêmica e seu envolvimento com o tema, ele elucida aspectos teórico-metodológicos referentes à história das ciências da saúde, destaca o potencial dos tratados e manuais de medicina como fonte e discute meios de acessibilidade a diferentes fontes para o redimensionamento de novos temas e objetos de estudo nesse campo de investigação.

Palavras-chave: história da medicina; ciência; corpo; tratados e manuais médicos; Império luso-brasileiro.

\section{Abstract}

The history of science is a growing and well-recognized area in Brazil, however, medicine during the colonial period is not well covered by research. Aiming to address this subject, this interview was carried out with Professor Jean Luiz Neves Abreu, an important researcher of the history of medicine during the LusoBrazilian Empire of the eighteenth century. By speaking of his personal career, his academic experience and his involvement with the subject, Professor Abreu clarifies theoretical and methodological aspects related to the history of health sciences. He highlights the potential of medical texts and manuals as a source and discusses means of accessibility and different sources that can allow new themes and objects to be reconsidered in this area of research.

Keywords: history of medicine; sicence; body; medical texts and manuals; the Luso-Brazilian Empire. 
Tean ean Luiz Neves Abreu, professor do Departamento e do Programa de Pós-graduação em História da Universidade Federal de Uberlândia, autor de vários trabalhos sobre história da religião, da ciência, da saúde e doença, das leituras e da medicina, é hoje um dos principais pesquisadores da história da medicina no Império luso-brasileiro, no século XVIII. Sua aproximação com esse tema se deu, a priori, por meio de pesquisas sobre a história da religiosidade popular em Minas Gerais colonial, assunto que abrange as práticas de cura e concepções de corpo dessa sociedade.

Esta entrevista faz parte do trabalho desenvolvido na pesquisa "Levantamento e catalogação de fontes para o estudo da história dos corpos na comarca de Vila Rica (1700-1808)", ${ }^{1}$ que teve por objetivo trazer à luz discussões acerca da historiografia das ciências, mediante a abordagem de questões sobre a medicina no Império luso-brasileiro, temática ainda pouco visitada pelos pesquisadores, principalmente em função das dificuldades de acessibilidade às fontes. Optou-se por tratar, primordialmente, aspectos teórico-metodológicos referentes ao assunto, com o intuito de, a partir da experiência, do conhecimento e dos trabalhos do professor Jean Abreu, focalizar concepções de medicina na América portuguesa, bem como a potencialidade dessa temática.

No depoimento, Jean Abreu versa sobre seus estudos acerca da história do corpo, destacando o trabalho com fontes que suscitaram seu interesse por essa temática, especialmente as concepções de medicina durante o século XVIII. Ao falar sobre o livro Nos domínios do corpo: o saber médico luso-brasileiro no século XVIII (Abreu, 2011), publicado pela Fundação Oswaldo Cruz, dá destaque às principais fontes utilizadas, aos tratados e manuais de medicina, ressaltando a importância de estudar também a circulação e o uso deles. Mais especificamente, aborda os estudos da história das ciências da saúde em Minas Gerais e seus desdobramentos.

A entrevista traz também relevantes considerações sobre processos de pesquisa em história das ciências, indica importantes bases de consulta, bem como possibilidades de acesso a tipos documentais ainda pouco trabalhados. Além disso, suscita temáticas para futuras pesquisas a partir do cruzamento de fontes e do entrelaçamento de diferentes abordagens da história, como história cultural, história das leituras e histórias das ciências.

Os autores

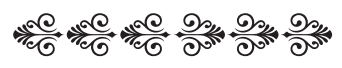

\footnotetext{
${ }^{1}$ Pesquisa financiada pela Fundação de Amparo à Pesquisa do Estado de Minas Gerais (Fapemig) e vinculada ao Núcleo de Estudos sobre o Corpo da Ufop, que mapeou, catalogou e disponibilizou fontes sobre a história do corpo, da saúde, da doença e higiene no período colonial. Um dos produtos desse trabalho foi o Catálogo de fontes história da saúde e das doenças na comarca de Vila Rica, disponível em: http://www.nec.ufop.br/catalogo.
} 
Atualmente percebemos, em função do surgimento cada vez maior de publicações, núcleos de pesquisa, eventos e discussões, que a história das ciências tem se configurado como área de pesquisa consolidada na historiografia brasileira recente. Temáticas como corpo, saúde e doença, que anteriormente apareciam nas frestas de alguns estudos históricos, hoje são objetos de várias pesquisas. Fale um pouco sobre sua inserção e trajetória nessa área de estudos: como se inseriu nessa área de pesquisa e em qual momento da sua trajetória acadêmica; no que tem trabalhado ultimamente e quais os projetos futuros?

Minha inserção foi um pouco ao acaso, porque durante o mestrado estudei religiosidade popular, trabalhei com práticas votivas e, já nos estudos dos ex-votos, percebi que vários eram relacionados à questão da saúde e da doença. Depois do mestrado, fiz algumas leituras e iniciei um projeto sobre história do corpo. No decorrer da pesquisa, encontrei uma diversidade enorme de fontes, que inseri na discussão sobre ciência. O projeto tomou norte completamente diferente, um eixo inesperado, tanto é que a linha em que me inseri no doutorado, na Universidade Federal de Minas Gerais (UFMG), foi história da cultura, e meu trabalho dialogou com a linha de história da ciência. A partir daí, procurei ampliar o diálogo com textos e discussões da história das ciências.

Você disse que o interesse, a opção pela história da saúde e história das ciências partiu da pesquisa que começou a desenvolver no mestrado.

Sim, no mestrado a temática era religiosidade, mas acabei trabalhando com a discussão sobre o corpo a partir dos ex-votos, pois grande parte deles tratava justamente de enfermidades e doenças, era um agradecimento a uma cura alcançada. Então comecei a trabalhar com o imaginário do corpo a partir dos ex-votos e também de outras fontes. O contato com os tratados médicos levou-me a perceber que havia um campo importante de estudo a ser percorrido, relacionado ao saber médico e às percepções sobre o corpo ao longo do século XVIII. Durante a pesquisa, procurei estabelecer um diálogo com estudos da historiografia brasileira, em particular com os trabalhos de Márcia Moisés Ribeiro (1997, 2003), Vera Beltrão Marques (1999), os estudos de Mary Del Priore (2009) sobre o corpo feminino, além do contato com os estudos relativos à saúde em Portugal, como o livro A história do corpo, de Jorge Crespo (1990), e os estudos de Rui Pita $(1996,1999,2000)$ sobre história da saúde e da farmácia em Portugal, já que minha pesquisa procurou dar conta do contexto luso-brasileiro. No âmbito dessa bibliografia, é importante situar alguns livros como Histoire du corps, coleção dirigida por Georges Vigarello (2005); Histoire de la pensée médicale en occident, coleção dirigida por Mirko Drazen Grmek (1997); e as obras de David Le Breton (1993), como La chair à vif: usages médicaux et mondains du corps humain.

O século XVIII, recorte temporal de suas pesquisas, ainda é pouco abordado, principalmente tomando Minas Gerais como recorte espacial. A importância de Minas no Império colonial português legou aos pesquisadores de hoje uma vasta gama de possibilidades temáticas, da qual a história das ciências, relativamente, ainda pouco se beneficia, se se considerar a potencialidade que o corpus documental, impresso, manuscrito e iconográfico, entre outros, tem a oferecer. Nesse sentido, um dos fatores que mais chama atenção no seu livro Nos domínios do corpo é o volume de fontes consultadas e o intenso trabalho de interpretação das mesmas. Entre cartas, estatutos, tratados e manuais de medicina 
publicados entre os séculos XVI e XVIII, são 74 referências trabalhadas no decorrer da pesquisa. Como foi o percurso desse trabalho e quais as principais dificuldades em lidar com um corpus documental de tal magnitude? Em um primeiro momento, com que tipo de fonte documental você teve contato?

O percurso é um pouco o de todo pesquisador. Primeiro é o trabalho de levantamento das fontes, que nem sempre é fácil e depende de uma série de fatores, como facilidade de acesso e até mesmo a sorte de encontrar alguma fonte ainda não visitada ou pouco explorada, como os lunários, almanaques que traziam uma série de informações baseadas na astrologia, dentre elas a influência dos planetas sobre o corpo humano e sua saúde. Em seguida vem o trabalho de localização das fontes. Por questões particulares, não foi possível viajar para Portugal, mas isso não foi um problema.

Hoje, graças à internet, temos uma facilidade muito grande de pelo menos encontrar referências dessas obras. A Biblioteca Nacional de Portugal, ${ }^{2}$ por exemplo, disponibiliza on-line a cópia pública de uma vasta gama de textos e fontes. Contei muito com a sorte de encontrar boa parte do material no Real Gabinete Português de Leitura, ${ }^{3}$ com facilidade de acesso à consulta. O Real Gabinete possui acervo importante para quem deseja pesquisar a história da saúde em Portugal e temas correlatos. Com relação ao acervo disponibilizado pelas bibliotecas virtuais, posso citar o Governo de mineiros, tratado médico relativo à saúde dos escravos, que se encontra disponível na página do Instituto de Estudos Brasileiros da Universidade de São Paulo. ${ }^{4}$ Há ainda fontes de extrema relevância disponíveis na Biblioteca Nacional de Portugal, a exemplo da obra Dissertation sur l'origine de la maladie vénérienne, de António Nunes Ribeiro Sanches (1765). ${ }^{5}$

O levantamento de informações nesse material foi o outro passo. Tive que sistematizar a leitura a partir dos eixos temáticos que eu estava desenvolvendo na tese. É sempre um processo de ida e volta. A primeira leitura nunca é definitiva, pois sempre voltamos para consultar novamente fontes já lidas, já que temos novas questões para responder ou buscar. O que acho mais interessante da leitura das fontes é que elas podem revelar novas questões a serem desenvolvidas no projeto. A principal discussão foi a de tentar entender as concepções de medicina, e isso só surgiu a partir dessa leitura. Além dos tratados médicos, trabalhei também com outras fontes impressas, como os lunários, conforme já mencionei, mas também memórias, artigos do Jornal Enciclopédico, publicado em Portugal em fins do Setecentos.

\section{A triagem e a releitura desse corpus documental lhe permitiram delinear sua problemática de pesquisa?}

Eu já tinha como principal objetivo identificar o discurso médico a respeito da doença, da cura e, sobretudo, do corpo, procurando compreender as permanências e as transformações

\footnotetext{
${ }^{2}$ Para a Biblioteca Nacional de Portugal, ver http://purl.pt/index/geral/PT/index.html.

${ }^{3}$ Para o Real Gabinete Português de Leitura, ver http://www.realgabinete.com.br/portalWeb.

${ }^{4}$ Para o Instituto de Estudos Brasileiros da Universidade de São Paulo, ver http://www.ieb.usp.br.

${ }^{5}$ António Nunes Ribeiro Sanches (1699-1783) foi um importante médico e intelectual português. Os principais argumentos de suas obras se relacionam à ideia de higiene como melhor forma de conservação da saúde dos povos em ambientes de propagação de doenças (vilas, navios, hospitais, prisões), e também de que o Estado tinha de garantir, com leis e coerções, a conservação da saúde das populações (Abreu, 2007). Dentre as obras de Sanches, destacam-se Tratado da conservação da saúde dos povos (1756) e Cartas sobre a educação da mocidade (1760).
} 
da medicina luso-brasileira ao longo do século XVIII. Nesse sentido, procurei me debruçar sobre fontes que tratavam da anatomia, bem como outros aspectos referentes ao conhecimento médico do Setecentos. Algumas dessas fontes são bastante conhecidas e já trabalhadas pela historiografia, como o Erário mineral (Ferreira, 1735). ${ }^{6}$ Outras, até onde foi possível perceber, tinham sido pouco utilizadas, como os chamados manuais de medicina doméstica publicados em Portugal, a exemplo das obras de Tissot $(1773)^{7}$ e Buchan (1788). ${ }^{8}$

Ao longo da pesquisa, foi possível observar como as percepções sobre o corpo humano visto como um microcosmo e máquina - desdobravam-se também em percepções sobre a saúde e a doença. O que pude verificar foi como, ao longo do século XVIII, houve sensíveis mudanças relativas à percepção do corpo doente, muitas delas ligadas à tentativa de romper com os princípios hipocráticos que fundamentavam a medicina luso-brasileira até então. Várias obras traziam à tona não somente uma crítica ao paradigma hipocrático, como também uma recusa à influência da religião e da magia na medicina. Tratava-se de, à luz da renovação do ensino da medicina, procurar transformar um quadro que os médicos adeptos da Ilustração consideravam ultrapassado. Havia claramente um esforço por parte dos médicos luso-brasileiros em dialogar com o conhecimento médico produzido para além do contexto ibérico e incorporá-lo em seus escritos.

Um detalhe na sua obra é o cuidado na leitura das fontes, uma vez que elabora uma reconstrução do contexto. Pode-se afirmar que você trabalhou com uma história intelectual?

Eu não me preocupei em definir meu trabalho por uma história das ideias ou história intelectual, mas de certa maneira considero que o estudo possui esse viés, pois se volta para a construção do pensamento médico no âmbito da cultura letrada. Por outro lado, busquei dialogar com a historiografia da ciência. A leitura do Fleck $(2010)^{9}$ e sua perspectiva de "coletivo de pensamento" me ajudou muito a entender a maneira como se constrói um conceito de doença, como isso passa por várias questões que não são meramente científicas e também pela discussão do aspecto cultural, que poderíamos chamar de extracientífico.

Dessa forma, talvez alguém possa ler meu trabalho como uma história das ideias acerca do corpo e da doença no século XVIII; entretanto, eu nunca me aprisionei muito em uma teoria

${ }^{6}$ O Erário mineral foi o primeiro tratado de medicina escrito em língua portuguesa. Nele estão reunidas experiências de práticas médicas realizadas pelo autor, Luis Gomes Ferreira, que foi cirurgião-barbeiro na capitania de Minas Gerais. Além da descrição pormenorizada dos principais males que ali eram frequentes, Ferreira aborda os meios mais eficazes de cura que experimentou, fazendo um importante inventário dos medicamentos utilizados na época com suas respectivas funções (Furtado, 2002).

${ }^{7}$ Samuel Auguste André David Tissot (1728-1797) foi um médico neurologista francês cuja obra mais conhecida é Aviso ao povo acerca da sua saúde (1773). Ciente da dificuldade de o conhecimento médico chegar a todos, escrevia às parteiras, sangradores e cirurgiões locais para que pudessem fazer a mediação entre os saberes medicinais e a medicina prática (Abreu, 2007).

${ }^{8}$ William Buchan (1729-1805) foi um médico escocês formado na Universidade de Edimburgo. Ficou conhecido na historiografia devido a seu interesse por instrução médica para públicos mais amplos e não apenas médicos e demais profissionais de cura. Sua obra mais conhecida é Medicina doméstica, ou, Tratado completo dos meios de conservar a saúde: trasladada em vulgar para utilidade da nação pelo doutor Francisco Pujol de Padrell Filho (1788).

${ }^{9}$ Ludwik Fleck (1896-1961) foi um médico polonês conhecido, sobretudo, pelo conceito de "pensamento coletivo", que se embasava numa perspectiva epistemológica orientada pelos fatores interacionistas de construção do conhecimento científico com o contexto social (Delizoicov, jun. 2002; Fleck, 2010). 
ou perspectiva teórica. No livro, tento dialogar na medida do possível com várias perspectivas, com vários autores, ou seja, ao mesmo tempo em que faço uso do Fleck, faço uso do Roger Chartier $(1998,2002,2004)$ e sua discussão sobre as práticas de leitura e apropriação. Minha entrada na história da ciência foi, portanto, por um caminho indireto, pelo viés da história cultural, com enfoque mais voltado para a história das ideias. Pensar o corpo e a doença é também lidar com a cultura na qual esses objetos estão inscritos e da qual o pensamento científico não é separado. Isso fica muito evidente no caso do século XVIII, quando se pensa nas influências de uma visão mágica e sobrenatural do mundo na formulação da ideia de doença.

Você realiza um extenso trabalho de elaboração de argumentos sobre o conhecimento anatômico na construção de saberes e concepções acerca do corpo e a formação do saber medicinal luso-brasileiro no século XVIII. Essas questões eram preocupações desde o início das pesquisas ou surgiram a partir do primeiro contato realizado com as fontes?

Isso fazia parte do horizonte inicial da pesquisa. $\mathrm{O}$ estudo das concepções sobre o corpo perpassava pelo conhecimento anatômico elaborado no século XVIII. Entretanto, no levantamento para a tese encontrei poucos tratados específicos sobre o assunto, como é o caso do Tratado completo de anatomia e cirurgia, de Manoel José Leitão (1788). Mas, ao longo da pesquisa, foi possível perceber que os outros compêndios de medicina e outras fontes, como os já citados lunários, faziam referências indiretas ao saber anatômico, tomado como parâmetro para pensar a doença e a saúde. Explico: as perspectivas do corpo como microcosmo e máquina - tema do primeiro capítulo -, predominantes na medicina do período, acabam se desdobrando em formas de abordar as causas das enfermidades e também na conservação da saúde. A ideia de que a saúde era regida pelos "temperamentos" e pelo equilíbrio desses ou por uma perspectiva sobrenatural da doença era abandonada por uma concepção do corpo como um mecanismo, regido pelas leis da física e da química. A concepção do corpo como máquina, mecanismo ao qual apenas o médico tinha acesso, passou a ser também o ponto de partida para estabelecer a relação entre as doenças e as alterações de certos órgãos.

Nesse trabalho, especificamente, a cuidadosa análise de manuais e tratados médicos do século XVIII é a base para a discussão que você realiza sobre concepções de corpo, cura e medicina, ao escrever sobre a construção do ideário e do saber medicinal luso-brasileiro no século XVIII - século esse, para as sociedades e para as ciências, permeado pelo antigo e pelo tradicional em franco debate com o novo e com o moderno. É instigante pensar se o conhecimento desses livros era absorvido e de que maneira, e, consequentemente, como era utilizado pelos agentes de cura na América portuguesa. Em pesquisas com os inventários do Termo de Mariana, conseguimos localizar em bibliotecas privadas de oficiais de cura, bem como nas dos letrados de outra área, boa parte dos manuais e tratados citados em seu livro, ou seja, a circulação existia. Mas, a grande questão é como aproximar o conteúdo desses livros a saberes e práticas de cura utilizados por seus proprietários, em seus respectivos contextos sociais. Você vê possibilidades de realização de cruzamentos entre essas tipologias de fontes? Se sim, gostaríamos que contasse alguma situação em que esse tipo de abordagem metodológica se fez necessária.

Eu não cheguei a desenvolver muito esse aspecto na pesquisa, mas acho que é extremamente válido, além de ser relevante e rico esse cruzamento de fontes. Sobre essa questão 
da apropriação das leituras, consegui mapear um pouco como alguns médicos citavam e se apropriavam de diversas teorias em seus tratados. Também foi possível observar a circulação desses tratados na colônia, o que pode ser percebido, como vocês mesmos mencionaram, nos inventários. ${ }^{10}$ Mas, tais cruzamentos escapavam aos objetivos da pesquisa.

$\mathrm{O}$ fato de vocês encontrarem nos inventários bibliotecas de indivíduos ligados às "artes de curar" é um indicativo de que essas obras chegavam a Minas e a outras partes da colônia e que tinham algum tipo de recepção. Resta saber como eram feitas essas leituras, de que modo esses livros influenciavam a prática médica. De certa maneira, procurei mostrar isso no livro ao apontar quais autores serviam de referência para os médicos luso-brasileiros.

Muitas referências bibliográficas que usei na pesquisa foram encontradas no inventário de Antônio José Vieira de Carvalho (Inventário..., 1905), cirurgião que exerceu sua prática nas Minas. Sua biblioteca continha vários títulos de tratados de medicina que, pode-se presumir, foram importantes em sua formação e na sua própria prática. Em seu inventário constam títulos como Observações sobre as enfermidades dos negros na França, de Jean Barthèlemy Dazille (1801) e Medicina doméstica, de Buchan (1788), entre outros.

Em seu trabalho você chegou a usar obras que não são do século XVIII?

Sim, no decorrer da pesquisa li tratados médicos do século XVII, mas poucos. Na verdade, a maior parte do corpus documental é do século XVIII.

Conforme escreveu, grande parte dos manuais de medicina era produzida principalmente para instruir as populações das regiões mais longínquas dos vastos domínios portugueses; porém, as possibilidades de se fazer uma história das leituras dessas obras, relacionando-as também com fontes manuscritas, ainda parece pouco palpável. A partir da sua experiência com manuais e tratados, e de seu conhecimento das trajetórias individuais de alguns desses autores do XVIII, quais as possibilidades e as evidentes dificuldades que destaca nas pesquisas sobre a história das práticas ou práxis de leituras medicinais no período?

Em trabalhos voltados para trajetórias individuais há, em geral, possibilidade de mapear a questão da leitura, ou seja, das apropriações de leituras que determinado autor fez. Agora, permanece o desafio de tentar saber até que ponto a obra desse autor foi lida ou não. Isso é uma questão que não coloquei no meu horizonte de análise, mas é relevante. Pretendo compreender o inverso, isto é, como esses autores escrevem os tratados? Quais autores leem? De que maneira na obra de António Nuno Ribeiro Sanches, por exemplo, é possível notar a influência de determinados autores que conformaram seus pensamentos a partir das poucas obras citadas ou pelas referências diretas ou implícitas? Outro desafio é localizar, justamente, as obras que servem de fundamento para esses médicos. Trata-se de tentar mapear a história de práticas de leituras desse ponto de vista.

\footnotetext{
${ }^{10}$ Alguns livros citados por Jean Abreu nesta entrevista e em suas publicações foram encontrados no acervo de inventários post-mortem da Casa Setecentista de Mariana, durante os trabalhos da pesquisa "Levantamento e catalogação de fontes para o estudo da história dos corpos na comarca de Vila Rica (1700-1808)", financiada pela Fapemig. Destaca-se, como exemplo, o inventário do cirurgião Antônio José Fernandes Machado (Inventário..., 1781), em cuja biblioteca, entre os mais de 49 livros de medicina, constam títulos como Polianteia medicinal, Medicina lusitana e Farmacopeia lusitana.
} 
A elaboração dessas obras, no século XVIII, exigia um amplo conhecimento de geografia e botânica. Muitas eram produzidas em um recorte espacial específico, a Europa. No entanto, várias chegavam ao Brasil colônia - recorte geográfico com clima, extensão territorial e trocas culturais intensos. Pensando na questão da práxis, em que a ambiência também se torna um espaço de absorção e reprodução de práticas e saberes, o que significa conhecimento das leituras nesse contexto? De que maneira se configuravam as formas de apropriação de conhecimento dessas leituras?

É interessante perceber como esses textos publicados por médicos luso-brasileiros estavam dialogando com a realidade colonial, ou seja, não eram mera reprodução dos tratados estrangeiros. Por exemplo, Francisco de Melo Franco ${ }^{11}$ escreveu vários textos de medicina no final do século XVIII, e sempre se reportava à realidade colonial.

Outro médico, José Pinto de Azeredo, ${ }^{12}$ autor que estudo atualmente, realizou uma pesquisa sobre a atmosfera do Rio de Janeiro, que foi publicada no Jornal Enciclopédico. Azeredo revelou conhecimentos de química e medicina adquiridos em sua formação na Europa. É perceptível o papel dinâmico que a leitura de textos estrangeiros feita por esses médicos assume na sua práxis. Considero que seus próprios textos devem ser lidos como uma dimensão de sua práxis. José Pinto de Azeredo (1799), por exemplo, escreveu um tratado sobre a enfermidade dos negros de Angola. O livro é muito interessante porque refuta uma série de teorias a partir de suas experiências. O que os estudos sobre medicina no Brasil colonial têm apontado é justamente o lugar desempenhado pela experiência na construção de um saber médico específico. Tais aspectos já se encontravam no Erário mineral, por exemplo, em que fica claro que, para o clima das Minas, não bastavam os conhecimentos definidos pela tradição. E isso se repete no caso da obra de Azeredo. Em Angola ele teve a oportunidade de observar como as doenças estavam relacionadas com uma série de questões específicas à região e aos costumes locais.

Por essa razão, os textos dos médicos são testemunhos importantes não somente de uma possível apropriação de conhecimentos divulgados em textos estrangeiros, mas também de sua própria prática. É possível perceber como eles constroem um discurso colocando sempre sua prática em evidência. Considero que é possível perceber no texto desses médicos e cirurgiões as marcas e apropriações de leituras que eles faziam. Pelo menos foi o tipo de leitura que fiz dessas obras. Outra coisa é ir para o arquivo e identificar obras nos inventários. Isso é outra dimensão desse trabalho sobre a leitura. São diferentes formas de encaminhar a discussão.

As pesquisas mostram, recorrentemente, a presença de tratados e livros de medicina/cirurgia nas bibliotecas de padres, professores e militares. Comente a necessidade de instrução e apropriação desses instrumentos por esses sujeitos no período colonial.

\footnotetext{
${ }^{11}$ Francisco de Melo Franco (1757-1822), médico luso-brasileiro, formado pela Universidade de Coimbra e defensor da medicina preventiva, foi considerado o primeiro puericultor brasileiro. Autor do primeiro livro de pediatria em língua portuguesa, intitulado Tratado da educação física dos meninos para uso da nação portuguesa (1790) (Tuoto, 2008).

${ }^{12}$ O médico José Pinto de Azeredo (1766?-1810), depois de passagem por Coimbra e pela Escócia, realizou análises do ar de diversas localidades do Rio de Janeiro. Aparentemente, seus ensaios se baseavam nas experiências sobre o ar fixo, do médico e químico escocês Joseph Black. Azeredo publicou seus escritos em Portugal, antes da chegada da imprensa ao Brasil (Kury, 2011).
} 
São obras que visam ser úteis para a comunidade, no que se refere à saúde de todos ou, como se dizia naquele contexto, "saúde dos povos". Outra coisa é encontrar diferentes tipos de documentos nos quais essas obras são referenciadas. A dificuldade consiste em saber se o sujeito possuía determinada obra para demonstrar sua pretensa erudição ou se realmente dela se apropriava como referência em sua prática, por exemplo de professores, padres ou capitães. Talvez fosse interessante mapear as devassas e verificar se há referências a alguns desses livros em bibliotecas de curandeiros, por exemplo. Será que os curandeiros possuíam esses livros? Nesses universos culturais diversos, as práticas mapeadas nas devassas acompanhavam o receituário médico? Será que havia um repertório comum das práticas de cura? Essas práticas de cura teriam relações com as raízes de cura africanas e na colônia agregaram as outras concepções?

É interessante notar, por exemplo, a questão da sangria, que é muito recorrente nas obras de medicina. Os índios e africanos sangravam. Por isso, nos indagamos: qual era o sentido que essa prática assumia de acordo com o filtro cultural específico? É certo que não necessariamente tinham um mesmo significado e sentido.

Como você interpreta os rumos da história das ciências? Você acredita que os estudos estão cada vez mais dependentes de corpora documentais extensos ou considera que boas temáticas podem ser abordadas com metodologias mais flexíveis, principalmente em casos de pesquisas que contam com curtos prazos de realização?

Essa questão possui vários desdobramentos, depende do que o pesquisador pretende. Há pesquisas que exigem levantamento de documentação primária maior, e outras que são voltadas para questões mais pontuais. O tipo de fonte com que trabalha o historiador da ciência também deve ser levado em consideração.

Recentemente participei de uma discussão sobre arquivos pessoais de cientistas que se encontram organizados, ou seja, possuem um corpus documental constituído. Se o pesquisador estudar a vida de determinado cientista que possuía um arquivo pessoal organizado, já torna a tarefa, eu não diria mais fácil mas, menos complexa.

Isso não significa que você vai se limitar àquele corpus documental. Do ponto de vista do conhecimento histórico, os desafios que se colocam para a história das ciências são os mesmos de outras dimensões do conhecimento histórico. Ou seja, o tipo de documento, o tamanho do corpus documental e a forma de trabalhá-lo dependem muito da escolha do pesquisador, dos caminhos metodológicos selecionados para sua pesquisa. É certo que, se decidir reconstituir um campo de conhecimento, terá o desafio de levantar uma série de dados em diversas fontes: primárias, jornais e publicações periódicas.

Entretanto, o pesquisador pode-se deter em determinados casos específicos. Por exemplo, se estudar um periódico médico ou de agricultura, se irá restringir a determinado corpus documental. Todavia, no decorrer da pesquisa, poderá fazer uso de outros documentos, mas tendo em vista que o norte da pesquisa será o objeto, nesse caso, o periódico.

A minha pesquisa é um bom exemplo. Escolhi como corpus documental principal textos, tratados e manuais. As memórias foram fontes incorporadas posteriormente. Além disso, houve flexibilidade, uma vez que realizei um recorte necessário para concretizar meu trabalho. Essa é uma tarefa que todo pesquisador deve realizar em sua pesquisa. 
Mais especificamente, como vê os estudos sobre a história das ciências da saúde em Minas Gerais e seus desdobramentos? Quais aportes teóricos, metodologias e temáticas de outros autores têm chamado sua atenção? Quais trabalhos destacaria?

Confesso que, depois que defendi minha tese, perdi um pouco o contato com a historiografia mais específica sobre Minas Gerais. Entretanto, há vários trabalhos que posso citar, como, por exemplo, o de Betânia Gonçalves Figueiredo (1998) sobre as artes e o ofício de curar no século XIX e o de Anny Jackeline Torres Silveira (2004) sobre a influenza em Belo Horizonte no século XX.

Outra referência importante é a obra Medicina mestiça, de Carla Berenice Starling de Almeida (2010), que apresenta um estudo sobre os cirurgiões, tese defendida na UFMG. Posso ser leviano por não citar outros autores, mas temos exemplos de trabalhos que estão na tradição da história das ciências e da saúde voltados para Minas Gerais. Isso demonstra a riqueza do corpus documental e das possibilidades de desenvolver pesquisas nesse campo. No Arquivo Público Mineiro, por exemplo, existem vários documentos que possibilitam a pesquisa sobre a história da saúde, vários caminhos e possibilidades de leitura e de objetos a serem pesquisados. De uma forma geral, isso tem sido notado no Brasil em alguns programas de pós-graduação, como os trabalhos desenvolvidos na Universidade Estadual de Campinas e na Fundação Oswaldo Cruz. É um campo muito amplo e em constante crescimento; basta ver os livros e teses publicados recentemente.

Tenho observado também que há um interesse cada vez maior por parte dos historiadores portugueses. No caso da história da medicina, sobre a qual posso falar mais, há vários congressos e colóquios, além de obras publicadas sobre o assunto. Outro dado importante é que há um esforço em disponibilizar as fontes ao pesquisador. Além da disponibilização on-line, os pesquisadores têm-se esforçado também para publicar as fontes que até então se encontravam restritas aos arquivos ou às bibliotecas de obras raras.

Há vários trabalhos de história das ciências que demonstram a vitalidade desses campos de estudo e as possibilidades de enfoques e temas.

\section{REFERÊNCIAS}

ABREU, Jean Luiz Neves.

Nos domínios do corpo: o saber medicinal lusobrasileiro no século XVIII. Rio de Janeiro: Editora Fiocruz. 2011.

ABREU, Jean Luiz Neves.

A colônia enferma e a saúde dos povos: a medicina das "Luzes" e as informações sobre as enfermidades da América portuguesa. História, Ciências, Saúde-Manguinhos, v.14, n.3, p.761778. 2007.

ALMEIDA, Carla Berenice Starling de. Medicina mestiça: saberes e práticas curativas nas Minas Setecentistas. São Paulo: Annablume. 2010.

AZEREDO, José Pinto de.

Ensaios sobre algumas enfermidades d'Angola dedicados ao Sereníssimo Senhor D. João Principe do Brasil. Lisboa: Regia Oficina Tipográfica. Disponível em: http://purl.pt/16429. Acesso em: 30 ago. 2011. 1799.

BRETON, David Le.

La chair à vif: usages médicaux et mondains du corps humain. Paris: Métailié. 1993.

BUCHAN, William.

Medicina doméstica, ou, tratado completo dos meios de conservar a saúde: trasladada em vulgar para utilidade da nação pelo doutor Francisco Pujol de Padrell Filho. Lisboa: Tipografia Rolandiana. 1788.

CHARTIER, Roger.

Leituras e leitores na França do Antigo Regime. São Paulo: EdUnesp. 2004. 
CHARTIER, Roger.

O mundo como representação. In: Chartier, Roger. À beira da falésia: a história entre certezas e inquietude. Porto Alegre: EdUFRGS. p.61-79. 2002.

CHARTIER, Roger.

A ordem dos livros: leitores, autores e bibliotecas na Europa entre os séculos XIV e XVIII. Brasília: EdUnB. 1998.

CRESPO, Jorge.

A história do corpo. Lisboa: Difel. 1990.

DAZILLE, Jean Barthèlemy.

Observações sobre as enfermidades dos negros, suas causas, seus tratamentos, e os meios de as prevenir. Trad. Antonio José Vieira de Carvalho. Lisboa: Arco do Cego. Disponível em: http://www.brasiliana.usp.br/bbd/ handle/1918/00622200page/1/mode/1u. Acesso em: 30 ago. 2011. 1801.

DEL PRIORE, Mary.

Ao sul do corpo: condição feminina, maternidades e mentalidades no Brasil colônia. São Paulo: Unesp. 2009.

DELIZOICOV, Demétrio et al.

Sociogênese do conhecimento e pesquisa em ensino: contribuições a partir do referencial fleckiano. Caderno Brasileiro de Ensino de Física, v.19, n. especial, p.52-69. jun. 2002.

FERREIRA, Luis Gomes.

Erário mineral, dividido em doze tratados. Lisboa: Oficina de Miguel Rodrigues. Disponível em: http://books.google.com.br/books/about/Erario_ mineral.html?id=pB8EUKIfz3AC\&redir_esc=y. Acesso em: 13 set. 2011. 1735.

FIGUEIREDO, Betânia Gonçalves.

$A$ arte de curar e os seus agentes no século XIX na província de Minas Gerais. Tese (Doutorado) - Programa de Pós-graduação em Sociologia, Universidade de São Paulo, São Paulo. 1998.

FLECK, Ludwik.

Gênese e desenvolvimento de um fato científico. Belo Horizonte: Fabrefactum. 2010.

FRANCO, Francisco de Melo.

Tratado de educação física dos meninos para o uso da nação portuguesa. Lisboa: Academia Real das Ciências. 1790.

FURTADO, Júnia Ferreira (Org.).

Erário mineral de Luís Gomes Ferreira. Belo Horizonte: Fundação João Pinheiro. Disponível em: http://books.scielo.org/id/ypf34. Acesso em: 16 set. 2011. 2002.

GRMEK, Mirko Drazen (Dir.)

Histoire de la pensée médicale en Occident. Paris: Éditions du Seuil. (v.2, De la Renaissance aux Lumières). 1997.
INVENTÁRIO...

Inventário dos bens móveis de Antônio José Vieira de Carvalho, capitão cirurgião-mor deste regimento de Cavalaria de Linha de Minas Gerais. Revista do Arquivo Público Mineiro, v.10, n.3-4, p.706-709. 1905.

INVENTÁRIO...

Inventário de Antonio José Fernandes Machado. $1^{\circ}$ ofício, códice 18, auto 520. (Arquivo Histórico da Casa Setecentista de Mariana, Mariana). 1781.

KURY, Lorelai.

A ciência útil em O Patriota (Rio de Janeiro, 18131814). Revista Brasileira de História da Ciência, v.4, n.2, p.115-124. 2011.

LEITÃO, Manoel José.

Tratado completo de anatomia, e cirurgia com um resumo da história de anatomia, e cirurgia, seus progressos, e estado dela em Portugal, t.2. Lisboa: Oficina de Antonio Gomes. Disponível em: http://books.google.com.br/books/about/ Tratado_completo_de_anatomia_e_cirurgia. html?id=3jCi6VZIXzEC\&redir_esc=y. Acesso em: ago. 2011. 1788.

MARQUES, Vera Regina Beltrão.

Natureza em boiões: medicinas e boticários no Brasil Setecentista. Campinas: Editora da Unicamp. 1999.

PITA, João Rui.

Medicina, cirurgia e arte farmacêutica na reforma pombalina da Universidade de Coimbra. In: Araújo, Ana Cristina (Coord.). O Marquês de Pombal e a Universidade de Coimbra. Coimbra: Imprensa da Universidade. p.129-162. 2000.

PITA, João Rui.

Um livro de 200 anos: a farmacopeia portuguesa (Edição oficial). A publicação da primeira farmacopeia oficial: Farmacopeia geral (1794). Revista de História das Ideias, v.20, p.47-100. 1999.

PITA, João Rui.

Farmácia, medicina e saúde pública em Portugal (1772-1836). Coimbra: Minerva. 1996.

RIBEIRO, Márcia Moisés.

Exorcistas e demônios: demonologia e exorcismo no mundo luso-brasileiro. Rio de Janeiro:

Campus. 2003.

RIBEIRO, Márcia Moisés.

A ciência dos trópicos: a arte médica no Brasil do século XVIII. São Paulo: Hucitec. 1997.

SANCHES, António Nunes Ribeiro.

Cartas sobre a educação da mocidade. Porto: Domingos Barreira. Disponível em: http://purl. pt/148/3/. Acesso em: 19 out. 2011. 1760.

SANCHES, António Nunes Ribeiro.

Dissertation sur l'origine de la maladie vénérienne, 
dans laquelle on prouve qu'elle n'a point été apportée de l'Amérique, \&t qu'elle a commencé en Europe, par une épidémie. Paris: chez P. Fr. Didot, le jeune. Disponível em: http://purl.pt/14696. Acesso em: 13 ago. 2011. 1765.

SANCHES, António Nunes Ribeiro.

Tratado da conservação da saúde dos povos. Lisboa: Bonardes e du Beux. Disponível em: http://books.google.com.br/books?id=_gI1 $\mathrm{MgXpNC8C \& printsec}=$ frontcover\&source $=\mathrm{g}$ bs_atbv=onepage \&q\&f=false. Acesso em: 14 set. 2011. 1756.

SILVEIRA, Anny Jackeline Torres. Influenza espanhola e a cidade planejada: Belo Horizonte, 1918. Tese (Doutorado) - Programa de Pós-graduação em História, Universidade Federal Fluminense, Niterói. 2004.
TISSOT, Samuel Auguste André David. Aviso ao povo sobre sua saúde. Tradução, Casa de Jorge Rey e Companhia. Lisboa: Oficina Patriarcal. Disponível em: http://books.google. com.br/books/about/Aviso_ao_povo_a_cerca_da sua_saude.html?hl=pt-BR\&id=RaYUAAAAQAAJA. Acesso em: 30 ago. 2011. 1773.

TUOTO, Elvio Armando. Francisco de Melo Franco (biografia). In: Tuoto, Elvio Armando. Biografias médicas by Dr. Elvio A. Tuoto. Brasil. Disponível em: http:// medbiography.blogspot.com/2008/05/franciscode-melo-franco.html. Acesso em: set. 2011. 2008.

VIGARELLO, Georges (Dir.).

Histoire du corps: de la Renaissance aux Lumières. Paris: Éditions du Seuil. 2005.

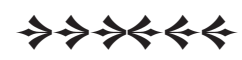

